\title{
PERBEDAAN GENERAL ARRANGEMENT DAN RASIO DIMENSI UTAMA KAPAL HIBAH YANG BERBASIS DI KABUPATEN PANGANDARAN DAN SUKABUMI
}

\author{
Differences in General Arrangement and Main Dimensional Ratio of Grant Ship Based \\ in Pangandaran and Sukabumi District
}

Oleh :

\begin{abstract}
Izza Mahdiana Apriliani, Alexander MA Khan, Achmad Rizal, Lantun Paradhita Dewanti
Program Studi Perikanan, Fakultas Perikanan dan Ilmu Kelautan, Universitas Padjadjaran, Indonesia
\end{abstract}

* Korespondensi : izza.mahdiana@unpad.ac.id

\begin{abstract}
The Ministry of Marine Affairs and Fisheries (KKP) has rolled out one of the programs, namely ship grants which aim to improve the welfare and production of capture fisheries. West Java Province is a priority for obtaining grant ships. This study aims to determine the general arrangement of grant ships based in the Pangandaran and Sukabumi districts and to calculate the ratio of the main dimensions of the vessels to see the characteristics of the vessels in supporting fishing operations. There are differences in general arrangements between grant ships in Kab. Pangandaran and Sukabumi, in Sukabumi, experienced many modifications by fishermen, namely the addition of buildings and masts. The value of the main dimension ratio of the grant vessel in the two regions is by the comparison value of the main dimension ratio of ships in Indonesia with the static gear operation method. The ratio value obtained shows weakness indicators, namely longitudinal strength and low stability. On this basis, the grant vessel is equipped with a vehicle to support fishing operations.
\end{abstract}

Keywords: fishing vessel, grant ship, main dimension

\begin{abstract}
ABSTRAK
Kementerian Kelautan dan Perikanan (KKP) menggulirkan salah satu dari program yaitu hibah kapal yang bertujuan untuk meningkatkan kesejahteraan dan produksi perikanan tangkap. Provinsi Jawa Barat menjadi prioritas memperoleh kapal hibah. Penelitian ini bertujuan untuk mengetahui general arrangement kapal hibah yang berbasis di Kabupaten Pangandaran maupun Sukabumi serta menghitung rasio dimensi utama kapal untuk melihat karakteristik kapal dalam mendukung operasi penangkapan. Terdapat perbedaan general arrangement antara kapal hibah di Kab. Pangandaran dan Sukabumi, di Sukabumi banyak mengalami modifikasi oleh nelayan yaitu penambahan bangunan dan tiang kapal. Nilai rasio dimensi utama kapal hibah di kedua wilayah telah sesuai dengan nilai pembanding rasio dimensi utama kapal di Indonesia dengan metode operasi static gear. Nilai rasio yang diperoleh menunjukkan indikator kelemahan yaitu kekuatan memanjang kapal dan stabilitas yang rendah. Atas dasar tersebut kapal hibah dilengkapi dengan katir dalam menunjang operasi penangkapan ikan.
\end{abstract}

Kata kunci: dimensi utama kapal, kapal hibah, kapal penangkapan

\section{PENDAHULUAN}

Kementerian Kelautan dan Perikanan (KKP) menggulirkan salah satu dari program yaitu hibah kapal yang bertujuan untuk meningkatkan kesejahteraan dan produksi perikanan tangkap. Berdasarkan Rusmilyansari et al. (2014), komponen dalam menentukan keberhasilan operasi 
penangkapan ikan selain dari nelayan dan alat tangkap adalah kapal pengoperasian alat tangkap. KKP memprioritaskan Provinsi Jawa Barat menjadi salah satu wilayah yang menerima hibah kapal, khususnya Jawa Barat bagian selatan.

Pesisir selatan Jawa Barat yang memiliki potensi di bidang perikanan tangkap diantaranya Kabupaten Sukabumi dan Pangandaran (Nurhayati 2013). Potensi tersebut menjadikan peluang di Kab. Pangandaran dan Sukabumi sebagai salah satu sentra produksi perikanan tangkap. Peningkatan nilai produksi di kedua wilayah tersebut diharapkan diiringi dengan meningkatnya kesejahteraan nelayan. Perwujudan hal tersebut perlu didukung salah satunya dengan adanya armada perikanan tangkap yang memadai dalam operasi penangkapan ikan.

Kapal perikanan merupakan salah satu unit penangkapan yang menjadi kunci utama dalam mendukung kegiatan operasi penangkapan ikan. Kapal perikanan turut menjadi salah satu faktor yang penting dalam meningkatkan hasil produksi upaya operasi penangkapan ikan untuk memenuhi kebutuhan pangan masyarakat yang berasal dari daging ikan (Palembang et al. 2013). Kesempurnaan kapal penangkap ikan baik dari segi desain ataupun konstruksinya mutlak diperlukan, karena akan mempengaruhi keberhasilan operasi penangkapan, keselamatan dan kenyamanan kerja selama di laut (Pasaribu 2010).

Kondisi perairan pesisir selatan Jawa Barat yang berhubungan langsung dengan Samudera Hindia mempengaruhi karakteristik kapal perikanan dalam pengoperasian alat tangkap di perairan tersebut (Apriliani et al. 2017). Kapal yang sesuai dengan penggunaan alat tangkap dan kondisi perairan dapat menunjang keberhasilan operasi penangkapan ikan. Keberhasilan suatu kapal penangkap ikan adalah apabila memenuhi 3 (tiga) faktor yaitu laik laut, laik operasi, dan laik simpan. Laik laut sangatlah berpengaruh terhadap performa kapal di laut sehingga desain kapal haruslah diperhatikan dan disesuaikan oleh kriteria standar kapal perikanan Indonesia (Azis et al. 2017).

Kapal hibah telah dimanfaatkan dalam pengoperasian alat tangkap gillnet. Kapal hibah yang dikelola di Kabupaten Pangandaran dan Sukabumi belum diketahui karakteristiknya untuk mengidentifikasi faktor keberhasilan penggunaan kapal tersebut. Berdasarkan kondisi perairan yang berada di pesisir selatan, perlu dilakukan penelitian untuk mengetahui general arrangement kapal hibah yang berbasis di Kabupaten Pangandaran maupun Sukabumi serta menghitung rasio dimensi utama kapal untuk melihat karakteristik kapal dalam mendukung operasi penangkapan.

\section{METODE}

Penelitian dilakukan pada bulan Agustus-September 2018 di Kabupaten Pangandaran serta pada bulan Agustus-September 2019 di Kabupaten Sukabumi. Objek penelitian yaitu kapal hibah dari Kementerian Kelautan dan Perikanan (KKP) yang berbasis di Kabupaten Pangandaran dan Sukabumi. Kapal hibah yang diberikan pada suatu daerah umumnya dikelola oleh Koperasi Unit Desa (KUD). Kapal hibah di Kabupaten Pangandaran tersebar pada pada 6 Tempat Pelelangan Ikan (TPI) yaitu TPI Legok Jawa, TPI Madasari, TPI Cikidang, TPI Nusa Wiru, TPI Bojong Salawe dan TPI Batu Karas. Sementara itu, kapal hibah di Kabupaten Sukabumi tersebar di 4 kecamatan pesisir yaitu Kecamatan Cisolok, Kecamatan Palabuhanratu, Kecamatan Ciemas dan Kecamatan Ciracap. Alat yang digunakan selama proses penelitian adalah alat ukur berupa meteran rol, water pass, tali tambang serta pendulum (bandul), alat tulis, perangkat komputer dan kamera.

Metode penelitian menggunakan metode deskriptif. Metode deskriptif bertujuan untuk membuat deskripsi, gambaran atau lukisan secara sistematis, faktual dan akurat mengenai faktafakta, sifat-sifat serta hubungan antar fenomena yang diteliti (Nazir 2011). Data yang diperlukan dalam penelitian ini berupa data primer dan sekunder. Data primer terdiri dari data ukuran dimensi utama kapal, bagian-bagian pada kapal, serta ukuran detail kapal yang diperlukan dalam menggambar general arrangement. Data sekunder berupa data jumlah dan sebaran kapal hibah yang diperoleh dari Dinas Kelautan dan Perikanan (DKP) setempat serta kajian pustaka dari penelitian sebelumnya.

Pengambilan data primer dilakukan dengan dengan observasi objek penelitian di lapangan. Objek berupa kapal hibah dengan melakukan pengukuran secara keseluruhan kapal yang terdapat pada masing-masing wilayah. Pengambilan data sekunder dengan wawancara kepada pihak 
(DKP) terkait dengan pengelolaan kapal hibah, jumlah dan sebaran keberadaan kapal hibah di Kabupaten Pangandaran maupun Sukabumi.

Data yang diperoleh selanjutnya dilakukan analis data. Analisis data menggunakan metode analisis deskriptif komparatif. Analisis ini digunakan untuk meggambarkan rasio dimensi dan gambaran umum kapal hibah serta membandingkan dengan kedua wilayah tersebut. Nilai rasio dimensi utama juga dibandingkan dengan nilai rasio dimensi utama kapal penangkapan ikan di Indonesia berdasarkan Iskandar dan Pujiati (1995) yang disajikan pada Tabel 1.

Tabel 1 Nilai rasio demensi utama kapal berdasarkan metode operasi di indonesia

\begin{tabular}{lccc}
\hline \multicolumn{1}{c}{ Metode operasi } & L/B & L/D & B/D \\
\hline Static gear & $2,83-11,12$ & $4,58-17,28$ & $0,96-4,68$ \\
Encircling gear & $2,60-9,30$ & $4,55-17,43$ & $0,56-5,00$ \\
Towed/Dragged Gear & $2,86-8,30$ & $7,20-15,21$ & $1,25-4,41$ \\
Multipurpose gear & $2,88-9,42$ & $8,69-17,15$ & $0,53-6,09$ \\
\hline
\end{tabular}

Keterangan : Iskandar dan Pujiati (1995)

\section{HASIL DAN PEMBAHASAN}

\section{Jumlah Kapal Hibah KKP di Kabupaten Pangandaran dan Sukabumi}

Pemerintah melalui Kementerian Kelautan dan Perikanan (KKP) memiliki kebijakan untuk selalu mempertahankan bantuan dalam bentuk subsidi maupun modal perikanan karena dapat membantu nelayan skala kecil atau tradisional (Luhur 2012). Bentuk program bantuan lainnya diantaranya yaitu pemberian kapal hibah pada beberapa daerah pesisir. Kabupaten Pangandaran dan Sukabumi salah satu dari daerah yang memperoleh bantuan modal berupa kapal perikanan.

Kapal hibah yang diterima oleh Kabupaten Pangandaran sejak tahun 2016 hingga tahun 2018 memiliki 2 ukuran yaitu 3 GT dan 5 GT dengan total kapal hibah sebanyak 55 unit. Ukuran kapal 3 GT sebanyak 33 unit, sedangkan ukuran kapal 5 GT sebanyak 22 unit. Kapal hibah tersebut dikelola oleh KUD yang disebar pada lokasi TPI di Kabupaten Pangandaran. Penyebaran serta jumlah kapal hibah berdasarkan TPI di Kabupaten Pangandaran disajikan pada Tabel 2.

Tabel 2 Penyebaran kapal hibah di Kabupaten Pangandaran

\begin{tabular}{lccc}
\hline & \multirow{2}{*}{ TPI } & \multicolumn{2}{c}{ Kapal Hibah } \\
\cline { 2 - 4 } & 3 GT (unit) & 5 GT (unit) \\
\hline Legok Jawa & 7 & - \\
Madasari & 6 & - \\
Cikidang & - & 22 \\
Nusa Wiru & 7 & - \\
Bojong Salawe & 7 & - \\
Batu Karas & 6 & - \\
\hline
\end{tabular}

TPI Cikidang merupakan penerima bantuan kapal hibah terbanyak pada pemberian tahun 2016 dan 2017 yaitu sebanyak 22 unit ukuran 5 GT. Penerima bantuan kapal hibah paling sedikit diterima oleh TPI Madasari dan TPI Batu Karas pada tahun 2018 sebanyak 6 unit dengan ukuran 3 GT. Penyebaran kapal berdasarkan Tabel 5 tidak tersebar merata di 6 TPI berdasarkan ukuran dan jumlah kapal yang disandarkan pada TPI tersebut. Hal tersebut dikarenakan pemberian dari kementrian yang memberikan kapal dengan berbeda ukuran. Selain itu, berdasarkan hasil wawancara dengan pihak Dinas Kelautan Perikanan dan Ketahanan Pangan Kabupaten Pangandaran menyatakan bahwa perbedaan pada setiap TPI dalam menerima jumlah bantuan kapal hibah atas pertimbangan jumlah anggota KUD disetiap TPI. Masih terdapat TPI yang tidak mendapatkan bantuan kapal hibah tersebut disebabkan oleh dasar legalitas kelompok nelayan pada TPI tersebut.

Kapal hibah yang diperoleh Kabupaten Sukabumi selama tahun 2017 hingga 2018 sebanyak 79 unit dengan 2 ukuran yang berbeda. Kapal berukuran 3 GT sebanyak 78 unit sedangkan ukuran 10 GT sebanyak 1 unit. Kapal hibah dikelola oleh KUD yang tersebar di 4 
kecamatan pesisir yang ada di Kabupaten Sukabumi. Sebaran kapal hibah berdasarkan ukuran kapal 3 GT yaitu Kecamatan Cisolok sebanyak 12 unit, Kecamatan Palabuhanratu sebanyak 32 unit, Kecamatan Ciemas 12 unit dan Kecamatan Ciracap sebanyak 22 unit. Kapal hibah dengan ukuran 10 GT disandarkan di Kecamatan Palabuhanratu. Perbedaan sebaran kapal hibah di Kabupaten Sukabumi didasarkan atas kebutuhan serta tingkat produktivitas pada masing-masing kecamatan.

\section{General Arrangement Kapal Hibah}

General arrangement (rancangan umum) kapal difokuskan pada desain dengan membuat tata letak ruang-ruang (layout), ruang di atas geladak, dudukan mesin dan bagian pendukung lainnya. Penempatan ruangan yang baik akan memberikan keleluasaan pada nelayan untuk bekerja diatas kapal, hal ini juga berpengaruh kepada stabilitas dan keselamatan kerja di atas kapal (Aziz et al. 2017). Berdasarkan Niam dan Hasanudin (2017) general arrangement digunakan untuk merencanakan ruangan yang dibutuhkan sesuai dengan fungsi dan perlengkapan kapal.

Kapal hibah yang ada di Kabupaten Pangandaran tidak memiliki dek (geladak). Tata letak peralatan di atas kapal tidak berdasarkan pengaturan kapal ikan pada umumnya, akan tetapi diatur sesuai keperluan nelayan. Kapal hibah baik yang berukuran 3 GT maupun 5 GT tidak memiliki perbedaan dalam general arrangementnya. Hal tersebut dapat dilihat pada Gambar 1.

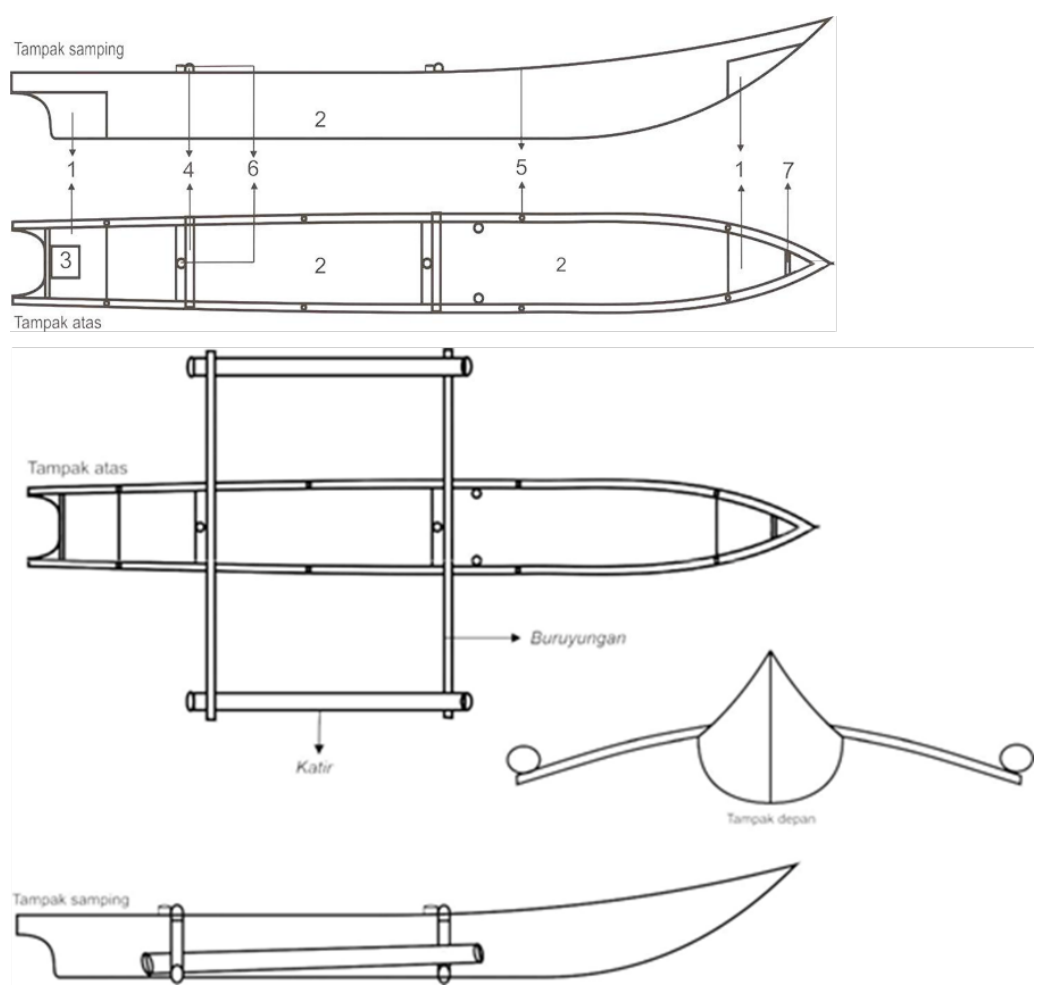

Gambar 1 General arrangement kapal hibah di Kabupaten Pangandaran

Keterangan:

(1) Ruang ballast

(2) Tempat alat tangkap dan palka ikan

(3) Tempat mesin

(4) Papan tempat mengikat katir

(5) Lubang untuk mengikat bambu

(6) Papan dan lubang tempat tiang

(7) Papan tempat tali jangkar

Gambar 1 menunjukkan general arrangement kapal hibah dalam mendukung operasi penangkapan ikan di Kabupaten Pangandaran yang cukup sederhana. Terdiri dari kelengkapan umum yang dibutuhkan dalam kapal penangkap ikan diantaranya ruangan yang dijadikan palka, 
tempat alat tangkap dan tempat untuk meletakkan mesin. Adanya beberapa kelengkapan tambahan pada kapal tersebut yaitu katir, papan tempat mengikat katir, lubang untuk mengikat bambu, papan dan lubang tempat tiang, serta papan tempat tali jangkar. Kelengkapan tersebut disesuaikan dengan keperluan nelayan dalam operasi penangkapan ikan.

Kapal hibah yang berbasis di Kabupaten Sukabumi memiliki 2 ukuran yaitu 3 GT dan 10 GT. General arrangement yang ditunjukkan pada Gambar 2 merupakan kapal ukuran 3 GT. Ukuran tersebut yang dijadikan dasar dalam perbandingan general arrangement baik di Kabupaten Pangandaran maupun Sukabumi. Rancangan umum kapal hibah ukuran 3 GT yang berbasis di Kabupaten Sukabumi sama halnya seperti dengan kapal-kapal hibah yang berbasis di Kabupaten Pangandaran, keduanya sama-sama tidak memiliki pengaturan kapal secara khusus namun diatur sesuai dengan kebutuhan nelayan dalam operasi penangkapan ikan. Kapal berukuran 3 GT ini tidak memiliki dek (geladak), palka maupun ruang mesin. Kapal hibah ini juga telah dimodifikasi oleh nelayan dengan penambahan katir. Katir merupakan alat tambahan kestabilan, mencegah gerakan oleng yang berlebihan pada perahu (Saksono 2009). Oleh karena itu, penambahan katir pada kapal hibah diharapkan dapat mengoptimalkan olah gerak kapal pada saat proses operasi penangkapan.

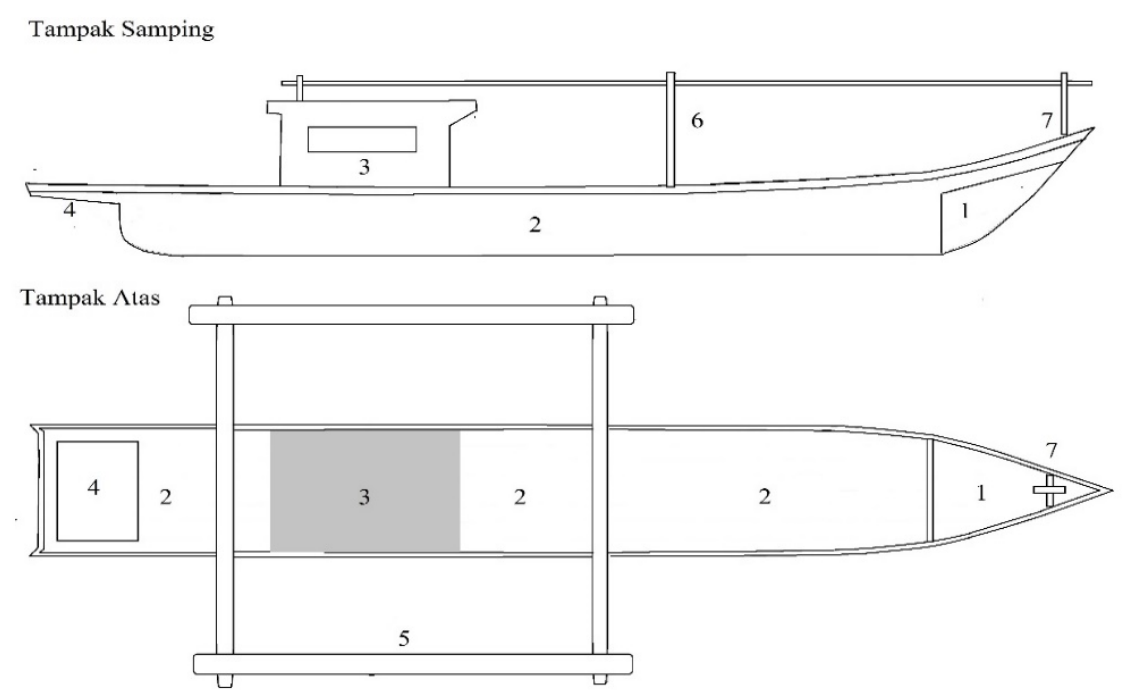

Gambar 2 General arrangement kapal hibah ukuran 3 GT di Kabupaten Sukabumi

Keterangan :

(1) Ruang ballast

(2) Tempak alat tangkap

(3) Ruang kemudi

(4) Tempat mesin

(5) Katir

(6) Tiang

(7) Tempat tali jangkar

Berdasarkan kapal hibah di Kabupaten Pangandaran maupun Sukabumi secara umum tidak memiliki perbedaan yang signifikan. Keduanya berbentuk perahu dengan bantuan mesin tempel. Kapal hibah tersebut difungsikan sebagai kapal penangkapan ikan, sehingga nelayan melakukan modifikasi agar mendukung aktivitas penangkapan. Bentuk modifikasi yang terlihat pada kedua wilayah tersebut yaitu berupa penambahan katir.

Dalam mendukung operasi penangkapan, salah satu bagian yang dibutuhkan berupa ruang kemudi atau tempat nelayan dalam mengoperasikan kapal maupun setting dan hauling alat tangkap. Kapal hibah di Kabupaten Sukabumi pun dimodifikasi dengan dibangun ruang kemudi. Namun untuk hibah kapal di Kabupaten Pangandaran hanya berupa papan untuk tempat nelayan mengemudikan kapal maupun mengoperasikan alat tangkap. 


\section{Rasio Dimensi Utama}

Berdasarkan Fyson (1985) dalam desain sebuah kapal, karakteristik perbandingan rasio dimensi utama merupakan hal penting yang harus diperhatikan untuk menentukan kapasitas kapal serta mengetahui stabilitas, kekuatan dan kecepatan kapal. Rasio dimensi utama meliputi perbandingan antara panjang dan lebar (L/B), lebar dan dalam (B/D) serta panjang dan dalam (L/D). Nilai yang diperoleh dari rasio dimensi utama tersebut selanjutnya dibandingkan berdasarkan nilai rasio dimensi utama berdasarkan metode operasi kapal penangkapan ikan di Indonesia berdasarkan Iskandar dan Pujiyati (1995). Sesuai dengan kondisi kapal hibah yang digunakan dalam operasi penangkapan dengan alat tangkap gillnet yang dioperasikan menetap di suatu perairan, dengan demikian nilai rasio akan dibandingkan berdasarkan metode operasi static gear.

\section{1) Rasio $L / B$}

Nilai rasio dimensi L/B pada Gambar 3 menunjukkan bahwa nilai rasio L/B kapal hibah di kedua wilayah masih sesuai dengan nilai rasio kapal penangkapan di Indonesia. Berdasarkan Palembang et al. (2013) nilai rasio L/B digunakan untuk menganalisis tahanan gerak dan kecepatan suatu kapal. Semakin kecil nilai rasio L/B, maka akan memperbesar tahanan gerak kapal yang akhirnya memperburuk terhadap kecepatan kapal.

Kapal hibah ukuran 3 GT di kedua wilayah memiliki nilai rasio L/B mendekati batas maksimum. Semakin besar nilai rasio L/B menunjukkan kapal memiliki tahanan gerak yang kurang baik namun memiliki kecepatan yang baik. Oleh karena itu, kapal dilengkapi dengan katir untuk dapat menutupi tahanan gerak tersebut.

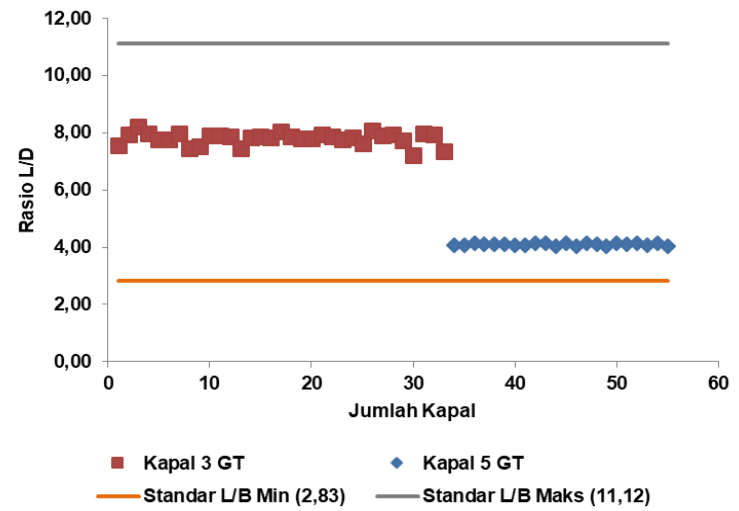

(a)

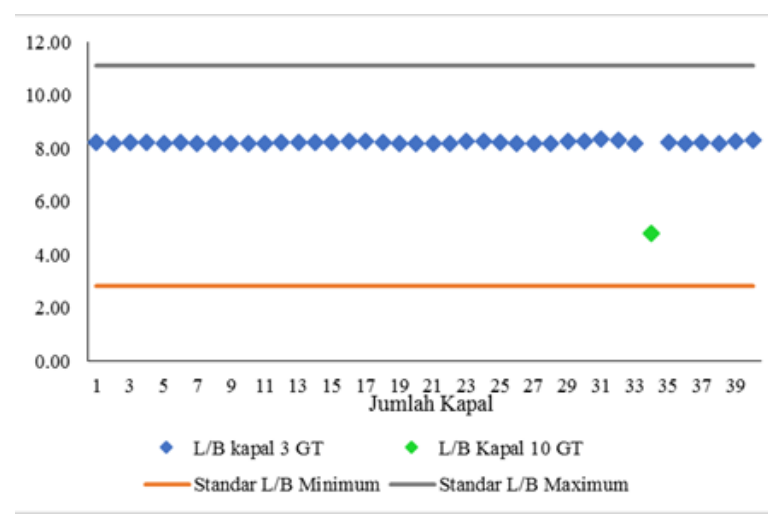

(b)

Gambar 3 Nilai rasio L/B kapal hibah (a) Kabupaten Pangandaran dan (b) Kabupaten Sukabumi

2) Rasio L/D

Gambar 4 menunjukkan nilai rasio L/D di kedua wilayah masih berada pada nilai acuan rasio dimensi utama kapal di Indonesia beradasarkan Iskandar dan Pujiyati (1995). Nilai rasio L/D adalah kekuatan memanjang suatu kapal. Nilai rasio ini menjelaskan seberapa kekuatan memanjang kapal, sehingga akan berpengaruh terhadap mudah tidaknya kapal tersebut patah pada saat mendapatkan gaya-gaya dari luar yang mempengaruhi kerja dari kekuatan kapal tersebut (Pangalila 2011). 


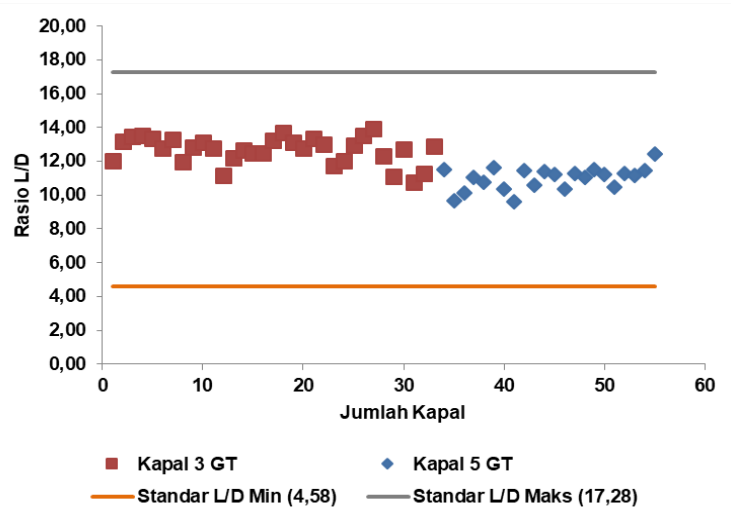

(a)

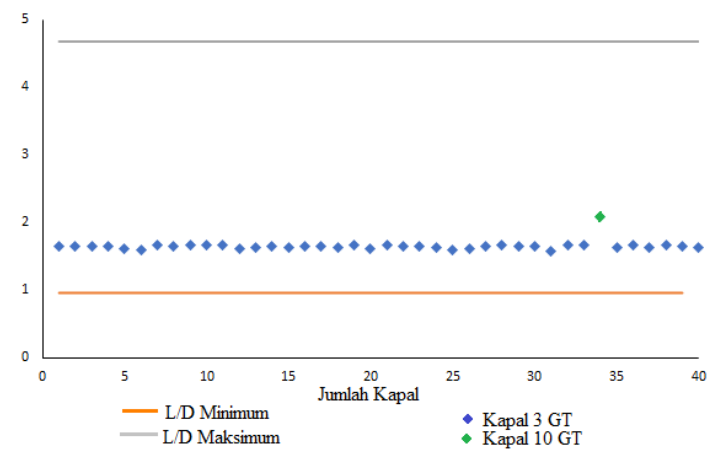

(b)

Gambar 4 Nilai rasio L/D kapal hibah (a) Kabupaten Pangandaran dan (b) Kabupaten Sukabumi

Nilai rasio L/D kapal hibah di Kabupaten Pangandaran (Gambar 4a) menunjukkan nilai yang mendekati batas maksimal. Semakin membesar nilai rasio L/D, maka akan mengakibatkan kekuatan memanjang kapal melemah (Palembang et al. 2013). Sedangkan kapal hibah di Kabupaten Sukabumi memiliki nilai yang mendekati batas minimal (Gambar 4b). Semakin mengecil nilai rasio L/D maka kekuatan memanjang kapal semakin kuat. Berdasarkan nilai tersebut, maka ada perbedaan antara nilai rasio L/D di kedua wilayah tersebut berdasarkan kekuatan memanjang kapal. Kapal hibah di Kabupaten Sukabumi memiliki kekuatan memanjang yang baik artinya kapal tersebut tidak rentan patah saat digunakan dan dapat menahan tenaga dorong dari ombak yang diterjang oleh kapal.

\section{3) Rasio B/D}

Berdasarkan nilai rasio dimensi B/D yang ditunjukkan pada Gambar 5 bahwa kapal hibah di kedua wilayah masih sesuai dengan nilai rasio kapal penangkapan di Indonesia. Menurut Palembang et al. (2013) nilai rasio B/D digunakan untuk menganalisa stabilitas dan kemampuan mendorong kapal. Semakin besar nilai rasio B/D maka stabilitas suatu kapal akan meningkat akan tetapi kemampuan mendorong akan berkurang.

Nilai rasio B/D di kedua wilayah menunjukkan nilai yang mengecil mendekati batas minimum. Hal ini menunjukkan bahwa kapal memiliki stabilitas yang menurun namun kemampuan mendorong yang meningkat. Menurut Nopandri et al. (2011), mengecilnya nilai rasio B/D akan mengakibatkan stabilitas yang buruk tetapi propulsi stabilitasnya akan meningkat. Bentuk mempertahankan stabilitas kapal, kapal hibah di kedua wilayah telah dimodifikasi dengan penambahan katir. Dengan demikian, kondisi stabilitas kapal dapat ditunjang dengan keberadaan katir di kedua sisi kapal dalam operasi penangkapan ikan.

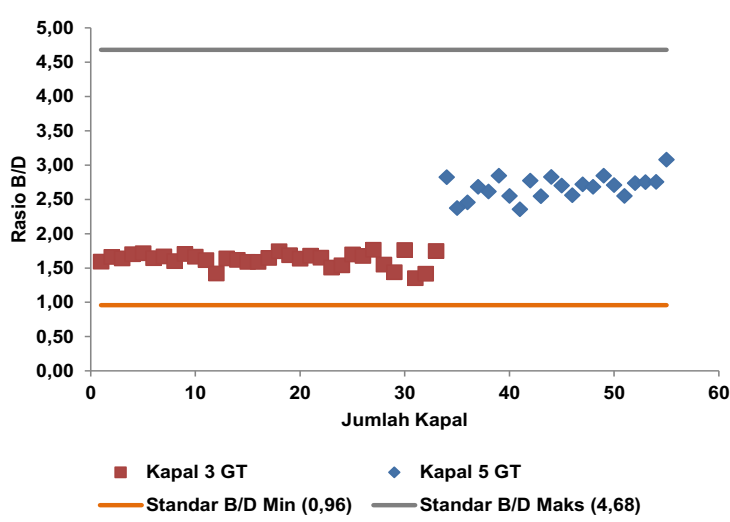

(a)

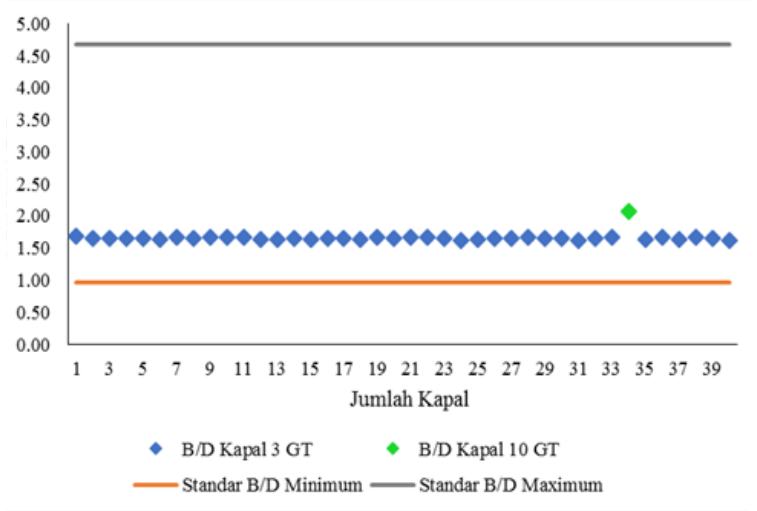

(b)

Gambar 5 Nilai rasio B/D kapal hibah (a) Kabupaten Pangandaran dan (b) Kabupaten Sukabumi 


\section{SIMPULAN}

Terdapat perbedaan general arrangement antara kapal hibah di Kab. Pangandaran dan Sukabumi, di Sukabumi banyak mengalami modifikasi oleh nelayan yaitu penambahan bangunan dan tiang kapal. Nilai rasio dimensi utama kapal hibah di kedua wilayah telah sesuai dengan nilai pembanding rasio dimensi utama kapal di Indonesia oleh Iskandar dan Pujiyati (1995) dengan metode operasi static gear. Nilai rasio yang diperoleh menunjukkan indikator kelemahan yaitu kekuatan memanjang kapal dan stabilitas yang rendah. Atas dasar tersebut kapal hibah dilengkapi dengan katir dalam menunjang operasi penangkapan ikan.

\section{DAFTAR PUSTAKA}

Apriliani IM, Dewanti LP, Zidni I. (2017). Karakteristik Dimensi Utama Kapal Perikanan Pukat Pantai (Beach Seine) di Pangandaran. Jurnal Airaha, 6(2): 48-53.

Azis MA, Iskandar BH, Novita Y. (2017b). Rasio Dimensi Utama dan Stabilitas Statis Kapal Purse Seine Tradisional di Kabupaten Pinrang. Jurnal Ilmu dan Teknologi Kelautan Tropis, 9(1): 19-28.

Fyson J. (1985). Design of Small Fishing Vessels. Italy (IT): Fisheries Industries Officer, FAO.

Iskandar BH, Pujiati S. (1995). Keragaan Teknis Kapal Perikanan di Beberapa Wilayah Indonesia. Bogor (ID): Jurusan Pemanfaatan Sumberdaya Perikanan FPIK IPB.

Luhur ES. (2012). Potret Subsidi Perikanan Tangkap Laut di Pelabuhanratu, Sukabumi. Buletin Riset Sosek Kelautan dan Perikanan, 7(1): 21-26.

Nazir M. (2011). Metode Penelitian. Jakarta (ID): Ghalia Indonesia.

Niam WA, Hasanudin. (2017). Desain Kapal Ikan di Perairan Laut Selatan Malang. Jurnal Teknik ITS, 6(2): 246-251.

Nopandri R, Fauziyah, Rozirwan. (2011). Stabilitas Statis Kapal Bottom Gillnet di Pelabuhan Perikanan Nusantara Sungai Liat Bangka Belitung. Maspari Journal, 2(1): 63-69.

Nurhayati A. (2013). Analisis Potensi Lestari Perikanan Tangkap di Kawasan Pangandaran. Jurnal Akuatika, 4(2): 195-209.

Palembang S, Luasunaung A, Pangalila FPT. (2013). Kajian Rancang Bangun Kapal Ikan Fibreglass Multifungsi 13 GT di Galangan Kapal CV Cipta Bahari Nusantara Minahasa Sulawesi Utara. Jurnal IImu dan Teknologi Perikanan Tangkap, 1(3): 87-92.

Pangalila FPT. (2011). Stabilitas Statis Kapal Pole and Line KM Aldeis di Pelabuhan Perikanan Aertembaga Bitung Sulawesi Utara. Jurnal Perikanan dan Kelautan Tropis, 7(1): 21-26.

Rusmilyansari, Iriansyah, Aminah S. (2014). Pembangunan Kapal Perikanan Di Galangan Kapal Tradisional Kalimantan Selatan. Fish Scientiae, 4(8): 95 - 109.

Saksono GA. (2009). Uji Tahanan Gerak Model Perahu Katir Palabuhanratu. Skripsi. Bogor (ID): FPIK IPB. 